\title{
FLIRT E ATOPIA: O CONTO-ENSAIO
}

Paulo Alexandre Pereira Universidade de Aveiro

\section{RESUMO}

No presente artigo, depois de expender algumas reflexões em torno da natureza transicional e atópica da forma ensaística, discute-se o modo como, em instâncias recorrentes de confluência intergenérica, no conto encontra acolhimento a pulsão indagativa e filosofante que constitui o proprium do ensaio. Com efeito, apesar do muito que, nos planos retórico e conceptual, parece separá-los, conto e ensaio partilham entre si afinidades histórico-genéticas e traços processuais que as três narrativas breves selecionadas para análise - de Fernando Pessoa, Jorge de Sena e Gonçalo M. Tavares não deixam de evidenciar. Nesse sentido, argumenta-se que, nestas ficções breves, em que a efabulação se compagina com a deriva abstrata ou especulativa, a retórica ensaística reveste insistente tonalidade autorrefleviva, convertendo o conto-ensaio num ensaio sobre o conto.

PALAVRAS-CHAVE: conto - ensaio - hibridismo genológico

\section{1.}

Desconcertada com um género esquivo, de linhagem segura mas de imponderável devir, a crítica tem-se sobretudo acercado do ensaio para nele acentuar uma pulsão literariamente herética que da sua substância parece ter-se tornado indistinguível. Dessa recalcitrância do ensaio em relação a todas as investidas teóricas nos dá conta Réda Bensamaïa (1987, p. 95-96), num estudo sobre o texto reflexivo de Barthes, em termos que, ao abrir esta reflexão, me interessa recuperar: 
A unique case in the annals of literature, the Essay is the only literary genre to have resisted integration, until quite recently, into the taxonomy of genres. No other genre ever raised so many theoretical problems concerning the origin and definition of its Form: an atopic genre or, more precisely, an eccentric one insofar as it seems to flirt with all the genres without letting itself be pinned down, the literary essay such as Montaigne bequeathed it to posterity has always had a special status (...).

Flirt e atopia parecem, pois, coligar-se como eixos conformativos do ensaio, forma incingível e apátrida, pelo que nela é intrinsecamente movente. Importa, desde logo, salientar que é precisamente essa natureza extraterritorial de um género errante numa no man's land tangencial à cartografia literária canónica, que o impulsiona a um flirt compulsivo com formas vicinais. À licenciosidade trânsfuga daquele que João Barrento (2010, p. 24) qualifica como o "menos imaculado dos géneros" não é, naturalmente, estranha a sua indeterminação epistemológica - via media entre ficção e filosofia - e morfologia proteica, que, conjugadamente, ajudam a explicar a impureza e apetência mimética do ensaio. Sabe-se que não é infrequente que, nas suas multiformes concretizações diacrónicas, ele se tenha disfarçado nos moldes formalizantes do diálogo filosófico ou da biografia, da epístola ou do tratado, do panfleto ou do romance, do aforismo ou do conto. Porque, sendo o seu "princípio [...] o da contaminação", o ensaio "não rejeita o incesto" (BARRENTO, 2010, p. 25) com outras formas literárias e paraliterárias, miscigenando-se com elas ou nelas se travestindo, num processo recursivo e fecundo de intergenericidade ${ }^{1}$.

Considerado, numa nomenclatura oscilante, que apenas em aparência se diria contraditória, como género misto, entregénero ou mesmo antigénero (LANGLET, 1995, p. 91) 2) é, em qualquer caso, sob o signo da errância - epistemológica, mas também composicional - que a trajetória desorbitada do ensaio em relação à constelação de géneros deverá ser entendida, como, aliás se deduz de um insistente agregado de metáforas que dele se tornou indesligável. Como salienta Irène Langlet (1995, p. 140), as figuras do nómada, da estrada, da viagem, ou do lugar de fronteiras instáveis são frequentemente convocadas para metaforizar esse tropismo peripatético do ensaio, vagabundagem do espírito e da letra, bem como a radical atopia de uma forma movente.

Máquina de emaranhar géneros, não é estranho que a dicção pessoal e reflexiva do ensaio surja frequentemente retonalizada pela inge- 
rência, mais ou menos pronunciada, da função narrativa, num fenómeno que poderia designar-se como epicização da forma ensaística. Como, referindo-se, em particular, à modalidade do ensaio narrativo, nota Douglas Hesse, são várias as modalidades de inscrição do modo épico - leia-se narrativo - no discurso ensaístico, podendo nele detetar-se distintos graus de narratividade: conviria, portanto, distinguir os ensaios que incorporam segmentos narrativos daqueles em que, efetivamente, se relata uma história, ou, ainda, daqueles outros que a si próprios se dão a ler como uma história (HESSE, 1982, p. 182). Limito-me a anotar, de passagem, que, ainda seguindo o mesmo autor, a narrativa não se limita a desempenhar, no tecido ensaístico em que surge transplantada, uma instrumental função argumentativa de ilustração ou de exemplum alegórico. O convívio coalescente de ensaio e narração parece antes deslocar estes textos híbridos para uma zona de fronteira, onde competirá, em última instância, ao leitor, uma vez aferida a vericondicionalidade do seu discurso ${ }^{3}$, contratualizar o seu modus recipiendi, escolhendo lê-los como ensaio ou como ficção.

2.

Pretendo aqui, no entanto, ocupar-me do processo correlativo ao da epicização do género ensaístico ou, mais simplesmente, da contaminação da narrativa pelo ensaio. Aliás, acredito, com Rosa Maria Goulart (2010, p. 87), que "uma fecunda pista de trabalho seria (...) a que empreendesse uma análise comparativa do ensaio narrativo, o ensaio que conta histórias, com as narrativas ficcionais, e não são raras, que incorporam nas suas histórias uma reflexão de tipo ensaístico". Mesmo reconhecendo tratar-se de uma senda crítica seguramente produtiva, não me deterei, nesta ocasião, na concepção actancial do ensaio como romance de ideias ou relato de aventuras, cujo andamento é regulado pela libido sciendi do seu autor, no âmbito do qual um ensaísta doublé em narrador encena os avanços e inflexões da sua argumentação, enunciando-os como se de peripécias narrativas se tratasse (LANGLET, 1995, p. 173).

Escolho privilegiar, de entre as várias espécies narrativas, o conto, sobretudo por me parecer que, como seria previsível, bem mais assídua atenção crítica tem sido dedicada ao romance-ensaio ${ }^{4}$. Praticado, desde finais do século XIX, por autores como Dostoevsky, Huysmans, Proust, Thomas Mann ou Robert Musil, sustentado por uma fórmula compositiva em que, em regime de intermitência completiva, alternam pensamento e narração, o romance-ensaio documenta, nas palavras de Stefano Ercolino 
(2014, p. vviii), a "Western tradition of philosophical mimesis, a literary vein in which the interaction between narration and concept is tight". São abundantes os exemplos desta impregnação da narrativa de ideias pela forma mentis e pelo ritmo elocutório do ensaio, patente, por exemplo, na densidade conceptualizante e na complexa arquitetura formal de um romance como O homem sem qualidades, de Robert Musil.

Comparativamente ao romance, é inegável que bem menos numerosas têm sido as abordagens teórico-críticas a ocupar-se do conto-ensaio, uma escassez em que pode, porventura, reconhecer-se a memória vestigial desse atavismo da margem que tem sido a condição vital de um género nascido sob o signo da subalternidade. Não são poucas, ainda assim, as afinidades que congraçam conto e ensaio numa estreita cumplicidade, expressa, desde logo, na origem excêntrica que a ambos converte em escritas de fronteira ${ }^{5}$. Esse parentesco é, antes de mais, genético. Como demonstrou Deborah Losse, desde os seus inaugurais Essais, Montaigne interpola, no seu discurso confessional-reflexivo, um multiforme thesaurus narrativo herdado da Antiguidade, reficcionalizando--o em função de estratégias técnico-discursivas pedidas de empréstimo aos conteurs dos séculos XV e XVI. Esta intrusão do conto relega o ensaio para a categoria híbrida dos discours bigarrés, o termo com que os contemporâneos de Montaigne designavam o estilo compósito, em que a narração surgia justaposta ao diálogo ou ao comentário (LOSSE, 2013, p. 103). Como sintetiza a autora $(2013$, p. 57$)$ "the essay, like the conte, demands the value added - the mutation and renewal of source material".

Do lado do conto, na sua reflexão precursora, Poe, o autor que reconhecidamente subscreve, com os estudos que dedica a um género então emergente, a sua certidão de nascimento teórica, não deixa de ressalvar, na primeira resenha das Twice-Told Tales, de Hawthorne, que as composições aí coligidas "não são de maneira alguma todas "contos". A maioria são ensaios propriamente ditos" (POE, 1842, p. 330). O escrúpulo desta distinguo prefacial não ilude, em todo o caso, o que, desde a génese da forma contística, se torna iniludível: a sua extrema permeabilidade às infiltrações lírico-reflexivas, que a fazem abeirar, não poucas vezes, do sketch estático ou do fragmento meditativo. Sabe-se, aliás, que o próprio Poe não ficou imune à tentação ensaística: em contos como "The Purloined Letter", "Never Bet the Devil your Head" ou "The Imp of the Perverse", por exemplo, são frequentes as ramificações cogitantes e especulativas do enredo, não hesitando o narrador em recorrer a uma retó- 
rica inquisitiva reminiscente do ensaio ${ }^{6}$. Há ainda quem, recuperando a fórmula consagrada por Poe de que a unidade de efeito perseguida pelo conto recomenda a sua leitura de uma assentada, a aplique ao ensaio literário, sustentando que "like most poems or short stories it [the essay] should be readable in a single sitting; readable but not entirely understandable the first or even the second time, and rereadable more or less forever" (CHADBOURBNE, 1983, p. 149).

Conto e ensaio partilham, por outro lado, uma relação de longa e fecunda solidariedade com a letra impressa. Se, consabidamente, as origens do conto moderno são indesligáveis da expansão do periodismo oitocentista e da voga romântica do folhetim, podendo, na realidade, o género nascente ser considerado "filho da locomotiva e da imprensa" (KIEFER, 2011, p. 14), também a prática do ensaio não prescindiu do espaço efémero de difusão de jornais e revistas, como bem atestam nomes de cultores tão destacados como os de Addison, Samuel Johnson, Emerson, Azorín ou Ortega y Gasset.

Não se esgotando nas condições extrínsecas da sua circunstância literária, a relação congenial que aparenta as escritas do ensaio e do conto parece radicar, antes, no plano imanente das respetivas poéticas. Hibridismo, descontinuidade, inacabamento, fragmentariedade, por exemplo, são, indiscutivelmente, leis generativas compartilhadas, em igual medida, por conto e ensaio. Sobre elas não nos alongaremos. Parece oportuno, ainda assim, recuperar aqui a imagem do conto como recorte, glosada em inúmeras teorizações sobre o género ${ }^{7}$, depois de Cortázar a ter proposto, no contexto da célebre analogia que estabelece entre conto e fotografia. O passo do ensaio do contista argentino é célebre, mas valerá a pena recordá-lo:

Nesse sentido, o romance e o conto se deixam comparar analogicamente com o cinema e a fotografia, na medida em que um filme é em princípio uma "ordem aberta", romanesca, enquanto que uma fotografia bem realizada pressupõe uma justa limitação prévia, imposta em parte pelo reduzido campo que a câmara abrange e pela forma com que o fotógrafo utiliza esteticamente essa limitação. [...] Fotógrafos da categoria de um Cartier Bresson ou de um Brassai definem sua arte como um aparente paradoxo: o de recortar um fragmento da realidade, fixando-lhe determinados limites, mas de tal modo que esse recorte atue como uma explosão que abra de par em par uma realidade muito mais ampla, como uma visão dinâmica que transcende espiritualmente o campo abrangido pela câmera. (CORTÁZAR, 2006, p. 151) 
Constituindo uma forma metonímica por excelência, a moldura constringente de que o conto cerca a tranche de vie nele ficcionalmente capturada torna explícito o primeiro mandamento da sua poética - a do silêncio semanticamente rendoso que deve circundar o núcleo centrípeto constituído pela sua efabulação mínima. Com efeito, se o recorte a que o conto procede é de ordem diegética, o do ensaio é antes de natureza epistemológica. Por isso, "el ensayo breve es a las grandes formas de pensamiento lo que el cuento puede ser a las grandes narraciones novelísticas" (TRABADO CABADO, 2005, p. 134) ${ }^{8}$.

Numa assunção programática de uma consubstancial incompletude, o ensaio sabe-se sondagem assistemática, sitiação tentativa, mas persistente, de um "núcleo ideativo", e, portanto, também ele metonímia fotográfica, como, em curiosa coincidência figurativa, argumenta João Barrento (2010, p. 82):

O molde mental, ou o modo de relação com o seu objecto, é no ensaio o de uma força de expansão metonímica, à semelhança do modo de actuação daquilo a que Barthes, em $A$ Câmara Clara, chama o punctum na fotografia: a partir de um centro, núcleo ideativo consistente, o ensaio expande-se, dissemina-se, constrói-se à imagem da ostra, do rizoma e da fuga, metáforas de formas diversas de construção do ensaio.

\section{3.}

Que o nome de Borges, convocado sobretudo em associação às suas parábolas de fundo gnóstico ou cabalístico, compareça em qualquer aproximação ao conto-ensaio (e, já agora, ao ensaio que conta) não causará grande perplexidade. Jaime Alazraki (1982, p. 10) observa que "Borges es tan inventivo, renovador y travieso en sus ensayos más memorables como en sus ficciones". Uma dessas travessuras consiste justamente na engenhosa convivialidade do lúdico e do erudito conseguida, na obra do escritor argentino, pela permuta intercomunicante de códigos de género que transitam do conto para o ensaio e deste para aquele. Como acrescenta ainda Alazraki (1982. p. 12), "con Borges, el ensayo adquiere una textura narrativa, e inversamente, el relato cobra una densidad ensayística". Deste modo, se o ensaio tende a replicar o arranjo narrativo ou a reeditar gestos processuais frequentes nas ficções breves, não é incomum que, por seu turno, estas funcionem como "maquinaria ensayística" (ALAZRAKI, 1982, p. 11). Contos justamente célebres, como "Pierre Menard, autor 
do Quixote" ou "Análise da obra de Herbert Quain", com a sua natureza derivativa e metatextual, mobilizam um aparato erudito - expresso na proliferação de notas, citações, datas ou referências bibliográficas, muitas vezes deslocadas em posição infrapaginal - e revelam uma compulsão discorrente bem mais coadunável com a lógica problemática e digressiva do ensaio do que com a efabulação ágil e parcimoniosa do conto. Note-se que a convocação de fontes, muitas vezes apócrifas, ou a abonação de uma pseudo-autoridade citacional, que saturam as ficções borgianas, se destinam a instaurar, mais propriamente, um efeito de ensaio. Só assim, como bem observa José Manuel Trabado Cabado (2005, p. 143), em Borges, "el cuento se convierte en la expresión narrativa de un sistema de ideas; es una escrita parásita que nace al abrigo de otros textos".

4.

Ora, se, no ensaio, é possível reconhecer uma narratividade graduada - recobrindo desde o traço narrativo espúrio ao relato interpolado ou ao ensaio-como-história -, são também distintas a incidência e funções da sua retórica em contexto ficcional. Proponho-me, por fim, dilucidar algumas das modalidades de translação ficcional do ensaio. Recorro, pelo seu potencial ilustrativo, a três narrativas: o conto intelectual "Num bar de Londres", de Fernando Pessoa; o "Conto brevíssimo", de Jorge de Sena e o romance serial ou ciclo de microficções Matteo perdeu o emprego, de Gonçalo M. Tavares.

Começo por destacar, ainda antes de me deter brevemente em cada um destes casos de ensaísmo ficcional, aquele que poderia considerar-se o grau zero do ensaísmo in fabula. Refiro-me aos contos cujo título parece funcionar como embraiador ensaístico, prescrevendo, por vezes em registo alegórico ou irónico, a sua leitura como demonstração narrativa da tese pressagiada pelo paratexto titular. O conto (ou romance, para o efeito pouco importa) apresenta-se, nestes casos, como expansão remática de um tema ensaístico, confirmação fabular de uma proposição apriorística. Um caso paradigmático são os Ensaios - sobre a cegueira e sobre a lucidez - de Saramago que, de resto, admitia que "provavelmente não sou um romancista; provavelmente sou um ensaísta que precisa de escrever romances porque não sabe escrever ensaios" (cit. em REIS, 1998, p. 46). Esse contrato de leitura ensaístico torna-se explícito na sintaxe alternativa de títulos de contos como - e cito exemplos aleatórios -, "A janela da despensa como argumento moral" ou "Brandina ou o silêncio dos produ- 
tos", de Luísa Costa Gomes (Contos outra vez), ou "O porco de Erimanto ou Os perigos da especialização" ou "O tio Florindo ou Os malefícios da poesia”, de A. M. Pires Cabral (O porco de Erimanto e outras fábulas). Sublinhe-se que, na desenvolução da sintagmática narrativa, muito pouco parece já aproximar estes contos do ensaio.

No conto intelectual de Pessoa, a compulsão dissertativa de um protagonista bêbedo e a substância abstrata e especulativa do seu discurso neutralizam a convencional orientação teleológica da intriga para o desenlace. A natureza ensaística do conto parece aqui indissociável do funcionamento dialético do seu discurso, evocativo da tradição dos diálogos platónicos de que o espírito do ensaio teria descendido. De facto, prescindindo em absoluto do telling narrativo, o conto reproduz o diálogo de duas personagens, ou, mais rigorosamente, o solilóquio disfarçado de um Bêbado que expende reflexões erráticas, a propósito das relações entre vida e arte, humanidade e natureza, inteligência e instinto ou que discorre sobre a metafísica das sensações, numa nítida duplicação dos mitos autorais do Pessoa sensacionista e do inconfundível andamento argumentativo dos seus próprios ensaios:

Não vemos, claro, mais do que a nossa sensação - mas porque há de ser errónea, em base e essência, a nossa sensação? Sustentar que ela é errónea na base quer dizer apenas que se sustenta que a nossa inteligência sabe mais que a nossa sensação, que a inteligência e não a sensação é o critério de realidade e verdade. Mas ou a inteligência nasce da sensação ou é coisa à parte. Se nasce da sensação não pode ter outro critério do que um basilarmente sensacional. Se a sua natureza é outra, de duas coisas uma: ou identifica realidade e verdade ou não. (PESSOA, 2012, p. 35)

Exibindo o seu talento disputativo - que o leva a concatenar argumentos, recorrendo à etimologia, à citação ou à enumeração didática -, o Bêbado não consegue, ainda assim, evitar a assertividade monológica do tratado, inimiga da maiêutica do ensaio. O que, em qualquer caso, interessa agora salientar é o modo como o aproveitamento dialético do ensaio, com o consequente deslassamento da intriga e a lentificação do tempo diegético, se encontra na origem de "um conto estático, onde todo o movimento é mental e consiste no fluxo de ideias entre dois seres, um que ensina e um que aprende" (FREITAS, 2012, p. 11)9. A preferência de Pessoa pelo conto-ensaio, isto é, de ficções em que predomina "o desenrolar de uma teoria, de um raciocínio, em que o autor dá um tratamento ficcional a questões filosóficas, metafísicas ou científicas" (FREITAS, 
2012 , p. 11), explica-se pelo facto de o autor ter reservado ao género uma função nitidamente supletiva, "onde são evidentes as conexões com a obra poética ou ensaística” (FREITAS, 2015, p. 6) ${ }^{10}$.

Essa linha unitiva entre as diferentes faces de uma obra multímoda é também evidente no caso de Jorge de Sena. No seu "Conto Brevíssimo", a pulsão ensaística de um criador crítico torna-se manifesta no tour de force autorreflexivo que o título remático da narrativa permite intuir. O ethos do ensaio manifesta-se, desta vez, no desdobramento narcísico do conto sobre a sua própria textualidade em processo e, em particular, na sabotagem irónica do diktat da brevidade a que, desde Poe, a forma tem sido submissa. O conto-ensaio de Sena converte-se, assim, num ensaio (paródico) sobre o conto ou, mais rigorosamente, sobre o seu cânone construtivo, aliás convocado pela epígrafe apócrifa atribuível a um arquiautor - A tale must be brief:

Este é um conto breve. É mesmo brevíssimo. De resto, se não fosse breve, muitíssimo breve, correria o risco de não ser um conto. A obrigação principal dos contos, mais do que dos homens, é conhecerem os seus limites. (...)

Claro que narrar não é, como todos sabem, o suficiente para escrever um conto. Mas também não é, como todos reconhecerão, uma coisa absolutamente necessária: mais, se o conto é breve, brevíssimo, o lugar para a narrativa estreita-se de tal modo, que ela quase não cabe; e, se a forçássemos, ela, como a intromissão das nossas pessoas o faria, ampliava os limites - aqueles limites que é preciso conhecer - para além do razoável num conto breve. (SENA, 1989, p. 167)

Considerando que "este escrito é, de facto, um conto, e não apenas uma reflexão de tipo ensaístico ou uma denegação narrativa", Maria Alzira Seixo (2000, p. 313-14) não deixa de reconhecer que nele "a manifestação metaficcional excede o horizonte regular da prática do género, e coloca a reflexão como ingrediente original na sua feitura (...)”. O que tanto a intrincada "fillosofia da composição", expendida pelo autor enquanto ensaísta, como o próprio conto-ensaio a escrever-se tornam evidente é que é, agora, a efabulação a sacrificar-se ao discurso reflexivo e não o inverso. Instrumentalmente chamada a ilustrar postulações de alcance metaliterário, uma anedota lateral protagonizada por uma velha londrina, num "misto de policial, de fantástico e de burlesco" (SEIXO, 2000, p. 316), demonstra, como bem viu ainda Maria Alzira Seixo (2000, p. 317), 
que "um conto brevíssimo é aquele que exibe a própria desistência de narrar, e que permite que o narrador passe incógnito (...)". Com efeito, dissimulado o contador por detrás da sua persona ensaística, não se verifica, em "Conto Brevíssimo", qualquer disjunção entre instância pensante e instância narrante.

Se, no caso do conto de Sena, a expansão inusitada do discurso metaliterário implica um recuo do narrativo, a radicalização das fronteiras entre ensaio e ficção torna-se ainda mais ostensiva num texto excêntrico, a vários títulos, como Matteo perdeu o emprego, de Gonçalo M. Tavares. É certo que a natureza intercomunicante dos géneros, insistentemente reivindicada pelo autor em depoimentos e entrevistas, é, em larga medida, responsável por objetos literários de difícil catalogação, em que se indistinguem ficção e pensamento, como acontece, por exemplo, com os volumes que compõem a série designada por Enciclopédia ${ }^{11}$ ou com o inclassificável Atlas do Corpo e da Imaginação. Esse acratismo arquitextual manifesta-se, em Matteo perdeu o emprego, por uma clivagem nítida das zonas de ficção e ensaio, originando uma dispositio inabitual. Os vinte e cinco relatos breves que integram a primeira parte do livro encontram-se ordenados alfabeticamente, a partir dos nomes dos seus protagonistas. Em cada um deles, a menção do nome da personagem que protagoniza a narrativa seguinte permite, por catáfora, anunciá-la, "criando uma espécie de estafeta narrativa em que cada personagem passa o testemunho à personagem seguinte" (SILVA, 2010). A este ciclo de contos surge anexado um apêndice intitulado "Notas sobre Matteo perdeu o emprego (Posfácio"), espécie de metatexto que retroativamente comenta a estrutura e o sentido dos relatos. Numa inesperada bifurcação funcional, que a cisão sintagmática do texto se encarrega de ludicamente acentuar, o autor é agora o seu próprio ensaísta, distanciando-se da sua ficção para sobre ela poder generalizar:

As ligações entre os vários acontecimentos de "Matteo". De facto a ligação não é entre $a$ e $b$, a ligação existe no mundo concreto dos acontecimentos; os acontecimentos ligam-se entre si, as personagens cruzam-se - e o alfabeto é apenas uma ordem exterior. (...)

De qualquer maneira, o narrador actua assim: o olhar fixa-se num pormenor de uma pequena narrativa e é este pormenor que faz a ligação com a pequena narrativa seguinte. (...) Há, de facto, aqui, como em qualquer romance ou obra de ficção, um sistema de ligações. A ligação parece evidente, mas outra ligação qualquer também o poderia parecer. 
Trata-se, como nas "falésias de mármore" de Jünger, de nos orientarmos no meio do horror. (TAVARES, 2010, p. 207-208)

Assumindo uma função didascálica em relação à série narrativa que o precede, este posfácio constitui um ensaio ficcional, uma vez que, como a respeito deste género salientou já Vincent Ferré (2009, p. 206), “diégèse et théories renvoient au même univers et que ces dernières sont tout aussi fictionnelles que le récit" e, portanto, "l'essai fictionnel est une mimèsis de ce discours non fictionnel qu'est l'essai (...)” (2009, p. 209). O sujeito ensaístico participa, deste modo, da mesma dinâmica de ficcionalização que funda a instância narrativa, ainda que se encontre fortemente coimplicado com o autor implícito ${ }^{12}$. O posfácio de Matteo perdeu o emprego funciona, assim, como indecidível corpo estranho, solicitando um regime de leitura intervalar, a meio caminho entre a instanciação reflexiva do ensaio e o jogo fictivo da efabulação.

\section{5.}

Desalojando o ensaio e a fícção do seu lugar ontológico, os contosensaio de que aqui nos ocupámos desfuncionalizam a distinção proposta, no estudo clássico de Sílvio Lima (1964), entre o ensaio sobre e o ensaio de: por mais excrescente que, na gramática tensa do conto, se venha a revelar a deriva ensaística, ela é sempre reconduzível à pessoalíssima dicção do seu autor. Eles demonstram, por outro lado, que o conto-ensaio é, também e sempre, um ensaio sobre o conto. E não deixam dúvidas, enfim, de que pode o ensaio habitar a casa da ficção, por mais breve (ou brevíssima) que esta seja. Nem sempre, pois, um conto é um conto é um conto. Às vezes, um conto é um ensaio é um conto. 


\section{ABSTRACT}

In this article, after some considerations pertaining to the transitional and atopic nature of the essay as genre, we discuss the recurrent instances of intergeneric confluence of the short story and the essay, by specifically focusing on those occasions when the philosophical and interrogative impulse commonly seen as the proprium of the essay finds its way into the short story. In reality, despite the conspicuous rhetorical and conceptual differences separating both genres, the short story and the essay share a historical and genetic kinship, as well as some compositional features, as the three short fictions selected in this article - by Portuguese writers Fernando Pessoa, Jorge de Sena and Gonçalo M. Tavares - will make evident. We will argue that in these short fictions, where the narrative fable is interspersed with abstract or speculative digressions, the essayistic tone seems inseparable from a self-reflexive intention, thereby converting the essay as short story in an essay on the short story.

KEYWORDS: short story, essay, genre hybridity

\section{NOTAS}

${ }^{1}$ Como sublinha Joel Haefner (1989, p. 265), "the essay evinces intergenreality, a dialogue of genres within a single text. [...] the essay encompasses, uses, exploits, and replies to a multiplicity of other genres".

${ }^{2}$ Sintetizando a diversidade de posicionamentos teóricos a propósito da relação entre o ensaio e a categoria de género, Irène Langlet (1995, p. 91) refere que "trois notions peuvent organiser la pensée des théoriciens. Nous les appelons notion de mixte, notion d'entre-deux et notion d'en-deçà".

${ }^{3}$ Como nota René Audet (s.d.), "la présence de la fiction dans l'essai peut également devenir envahissement, lorsque le mélange se fait plus marquant que la simple intégration de fictions illustratives. Les textes peuvent croiser les deux formes, conjuguant de diverses façons leurs spécificités discursives et énonciatives”.

${ }^{4}$ É o caso dos estudos recentes de Vincent Ferré (2013). L'essai fictionnel: essai et roman chez Proust, Broch, Dos Passos. Paris: Honoré Champion, e de Stefano 
Ercolino (2014). The Novel-Essay, 1884-1947. New York: Palgrave Macmillan. ${ }^{5}$ Como lembra Viorica Patea (2012, p. 7), "its long-standing theoretical neglect, though, made the short story appear to be "a form at the margins". Seen as excentric and at the low end of the hierarchy of arts - contrary to Poe's earlier vision - the short story began to be invested with the vindicating powers of the wronged and the underrated. The first to attribute subversive powers to the genre was the Irish writer Frank O'Connor, who defined the short story as the "lonely voice" of "outlawed figures wandering about the fringes of society".

6 Partindo de uma leitura de "A Carta Roubada" de Poe, Abel Barros Baptista (2010, p. 59-69) expende estimulantes (e provocatórias) reflexões sobre a relação entre conto e ensaio em "O desaparecimento do ensaio".

${ }^{7}$ Sobre o conto como recorte, leia-se, por exemplo, o estudo de Luiz Carlos Santos Simon (2007), "O conto e o pós-modernismo: recorte, velocidade e intensidade".

${ }^{8}$ Acrescenta ainda o autor: "El pensamiento aforístico como derrumbe de los grandes sistemas crea pasadizos con las narraciones mínimas. El pensamiento dialoga con la narración y cuando ambas formas de escribir eligen la miniatura llegan a confundirse. El cuento brevísimo propone una incertidumbre, el ensayo mínimo abre una puerta a una revelación: en ambos casos se constata una revisión de lo aceptado". (TRABADO CABADO, 2005, p. 137)

${ }^{9}$ Como nota Ana Maria Freitas (2012, p. 11), "aquilo que Pessoa designa por contos intelectuais, para os quais prevê um ou mais volumes, são histórias baseadas em conceitos filosóficos, desenvolvidos em diálogos de mestre para discípulo. É frequente, nas ficções pessoanas, o desenrolar de uma teoria, de um raciocínio, em que o autor dá um tratamento ficcional a questões filosóficas, metafísicas ou científicas".

${ }^{10}$ Referindo-se às ficções pessoanas coligidas no volume A Estrada do Esquecimento e outros contos, Jorge Uribe (2016, p. 566) salienta como aí "reaparecem especulações filosóficas semelhantes àquelas reunidas em $O$ Mendigo e outros contos, como, por exemplo, "Uma Tarde Clerical" ou "A Perda do Hiate Nada", mas também surgem textos que mais claramente correspondem a uma linha de desenvolvimento narrativo que teve como precursores Edgar A. Poe, O’Henry e Ambrose Bierce, todos autores que fizeram parte dos projetos de tradução pessoanos, sendo que os dois primeiros chegaram efetivamente a ser publicados em tradução nas páginas da revista Athena".

${ }^{11}$ Breves Notas sobre a Ciência (2006), Breves Notas sobre o Medo (2007) e Breves Notas sobre as Ligações (2009).

${ }^{12}$ Numa aproximação à questão da ficcionalidade do ensaio, refere $\mathrm{M}^{\mathrm{a}}$ Elena Arenas Cruz (1997, p. 121): “(...) la dimensión ficcional del ensayo no se puede 
reducir al hecho de que en la argumentación aparezcan algunos fragmentos textuales de carácter ficcional. (...) Así puede hablarse teóricamente de que el autor de ensayos se nos presenta a través de la construcción imaginaria de un yo que resulta mucho más atractivo y sugerente para asentar la credibilidad de la argumentación, o de que las pruebas se fundamenten en premisas verosímiles, útiles para hacer parecer verdadero el contenido del razonamiento. Pero además resulta que hay algunos ensayos en los que los mecanismos convencionales de la representación ficcional del mundo son precisamente la base de su construcción textual”.

\section{REFERÊNCIAS}

ALAZRAKI, Jaime. Tres formas del ensayo contemporáneo. Revista Iberoamericana, Pittsburgh: University of Pittsburgh, v. XLVIII, n 118-119, p. 9-20, 1982. AUDET, René. La fiction à l'essai. fabula. La recherche en littérature. Disponível em : <http://www.fabula.org/colloques/frontieres/215.php>. Acesso em: 8 fev. 2017.

BAPTISTA, Abel Barros. O desaparecimento do ensaio. In: GOULART, R. M. (Org.). Poéticas do Ensaio. Coimbra: Centro de Literatura Portuguesa-Universidade de Coimbra/Universidade dos Açores, 2010, p. 59-69.

BARRENTO, João. O Género Intranquilo. Anatomia do ensaio e do fragmento. Lisboa: Assírio \& Alvim, 2010.

BENSAMAÏA, Réda. The Barthes Effect: The essay as reflective text. Minneapolis: University of Minnesota Press, 1987.

CHADBOURNE, Richard M. A Puzzling Literary Genre: Comparative Views of the Essay. Comparative Literature Studies, Pennsylvania: Penn State University, v. 20, nº 2, p. 133-153, 1983.

CORTÁZAR, Julio. Alguns aspectos do conto. In: Valise de Cronópio. Tradução de Davi Arriguci Jr. e João Alexandre Barbosa; organização de Haroldo de Campos e Davi Arriguci Jr. 2 ed. São Paulo: Perspectiva, 2006, p. 147-163.

ERCOLINO, Stefano. The Novel-Essay, 1884-1947. New York: Palgrave Macmillan, 2014.

FERRÉ, Vincent. Le saveur de l'essai: Proust et l'essai fictionnel. Poétique, Paris, v. 158, nº 2 , p. 201-213, 2009.

FREITAS, Ana Maria. Nota Introdutória. In: PESSOA, Fernando. O Mendigo e outros contos. Lisboa: Assírio \& Alvim, 2012, p. 7-17. 
FREITAS, Ana Maria. Nota Introdutória. In: PESSOA, Fernando. A Estrada do Esquecimento e outros contos. Lisboa: Assírio \& Alvim, 2015, p. 5-18.

GOULART, Rosa Maria. O ensaio: convenções de género e opções discursivas. In: - (Org.). Poéticas do Ensaio. Coimbra: Centro de Literatura Portuguesa-Universidade de Coimbra/Universidade dos Açores, 2010, p. 85-97.

HAEFNER, Joel. Unfathering the Essay: Resistance and intergenreality in the essay genre. Prose Studies: History, Theory, Criticism, Columbus-Ohio: The Ohio State University, v. 12, no 3, p. 259-273, 1989.

HESSE, Douglas. Stories in Essays, Essays in Stories. In: ANDERSON Chris. (Ed.). Literary Nonfictions: Theory, Criticism, Pedagogy. Carbondale: Southern Illinois University Press, 1989, p. 176-196.

KIEFER, Charles. A Poética do Conto: De Poe a Borges um passeio pelo gênero. São Paulo: Leya, 2011.

LANGLET, Irène. Les théories de l'essai littéraire dans la seconde moitié du XXème siècle. Domaines francophone, germanophone et anglophone: Synthèse et enjeux. 569 p. 1995. Tese (Doutoramento em Literatura Geral e Comparada) - Université de Rennes 2, Rennes-Haute Bretagne.

LIMA, Sílvio. Ensaio sobre a essência do ensaio. Coimbra: Arménio Amado Editor, 1964.

LOSSE, Deborah N. Montaigne and Brief Narrative Form: Shaping the Essay. New York: Palgrave Macmillan, 2013.

PATEA, Viorica. The Short Story: An Overview of the History and Evolution of the Genre. In: _ (Ed.). Short Story Theories. A Twenty-First-Century Perspective. Amsterdam-New York: Rodopi, 2012, p. 1-24.

PESSOA, Fernando. Num Bar de Londres. In: O Mendigo e outros contos. Lisboa: Assírio \& Alvim, 2012, p. 33-37.

POE, Edgar Allan. Primeira resenha de Edgar Allan Poe sobre Twice-told tales, de Nathaniel Hawthorne. In: KIEFER, C. A Poética do Conto: De Poe a Borges um passeio pelo gênero. São Paulo: Leya, 2011, p. 329-332.

REIS, Carlos. Diálogos com José Saramago. Lisboa: Editorial Caminho, 1998.

SENA, Jorge de. Conto Brevíssimo. In: Antigas e Novas Andanças do Demónio. Lisboa: Edições 70, 1989, p. 167-169.

SEIXO, Maria Alzira. O lugar para a narrativa. Sobre o conto de Jorge de Sena, a partir de "Conto Brevíssimo", "A Janela da Esquina" e "A Comemoração". In: FAGUNDES, Francisco Cota; GÂNDARA, Paula. (Orgs.). "Para emergir nascemos...”. Estudos em Rememoração de Jorge de Sena. Lisboa: Edições Salamandra, 2000, p. 313-323. 
SILVA, José Mário (2010). Dois novos livros de Gonçalo M. Tavares. Jornal Expresso, 17 dez. 2010. Disponível em: <http://expresso.sapo.pt/cultura/Livros/ dois-novos-livros-de-goncalo-m-tavares=f621198>. Acesso em: 8 jan. 2018.

SIMON, Luiz Carlos Santos. O conto e o pós-modernismo: recorte, velocidade e intensidade. Revista Investigações, Recife: Universidade Federal de Pernambuco, v. 20, nº1, p. 127-148, 2007.

TAVARES, Gonçalo M. Matteo perdeu o emprego. Porto: Porto Editora, 2010.

TRABADO CABADO, José Manuel. La escritura nómada. Los límites genéricos en el cuento contemporáneo. León: Universidad de León-Servicio de Publicaciones, 2005.

URIBE, Jorge. Autor in fabula. Fernando Pessoa contista. Pessoa Plural, Providence: Brown University, nº 9, p. 564-570, 2016.

Recebido:26/01/2018

Aceito: 07/06/2018 